\title{
Does the prevalence of the metabolic syndrome improve by applying the International Diabetes Federation criteria?
}

\author{
A Soto González ${ }^{1, *}$, D Bellido Guerrero ${ }^{1}, M$ Buño Soto ${ }^{1}, S^{2}$ Pérega Díaz², D De Luis ${ }^{3}$, \\ M Lopez de la Torre ${ }^{4}$ and M Martínez Olmos ${ }^{5}$ \\ 'Department of Endocrinology and Nutrition, Hospital Juan Canalejo, La Coruña (Servicio de Endocrinología y \\ Nutrición), Xubias de Arriba no 84, 15006 A Coruña, Spain: ${ }^{2}$ Clinical and Statistical Epidemiology Unit, \\ Hospital Juan Canalejo, La Coruña, Spain: ${ }^{3}$ Department of Endocrinology and Nutrition, Rio Hortega, \\ Valladolid, Spain: ${ }^{4}$ Department of Endocrinology and Nutrition, Hospital Virgen de la Torre, Granada, Spain: \\ ${ }^{5}$ Department of Endocrinology and Nutrition, Hospital Mexoeiro, Vigo, Spain
}

Submitted December 2006: Accepted April 2007

\begin{abstract}
Objective: To estimate the prevalence of the metabolic syndrome (MS) in a population of patients with overweight and obesity of the A Coruña and Granada health areas, using the definitions of the Third Report of the National Cholesterol Education Program Expert Panel on Detection, Evaluation and Treatment of High Blood Cholesterol in Adults (ATP III) and of the International Diabetes Federation (IDF).

Patients and methods: During a period extending from 1996 to 2003, only those patients attending endocrinology outpatient clinics for whom all the anthropometric and biochemical parameters used to define the MS, both according to the ATP IIII and the IDF, were available were selected. The final study sample consisted of 285 patients, 198 females (69.5\%) and 87 males (30.5\%).

Results: The prevalence of the MS was 29.8\% when the ATP III definition was applied, and $41.1 \%$ according to the IDF criteria. Prevalence by sex was $32.2 \%$ in men and $28.8 \%$ in women according to the ATP III, and $42.5 \%$ and $40.4 \%$, respectively, according to the IDF.

Conclusions: In a patient population with overweight or obesity, the prevalence of the MS is higher when the IDF criteria, instead of the ATP III criteria, are used. These findings may have significant implications when it comes to addressing early diagnosis of cardiovascular disease and diabetes mellitus in these patients, in order to perform therapeutic measures at the initial stages and thereby reduce metabolic and cardiovascular complications.

Keywords
Prevalence
Definition of the metabolic syndrome
Insulin resistance
\end{abstract}

The factors associated with an increased risk of developing diabetes mellitus ${ }^{1}$ or cardiovascular disease (CVD) ${ }^{2}$ include, but are not limited to, advanced age, physical inactivity, high blood pressure, low high-density lipoprotein (HDL) levels, high triglyceride levels, hyperglycaemia and obesity. Many of these risk factors are the ones that make up the so-called syndrome $\mathrm{X}^{3}$, insulin resistance syndrome $^{1}$ or metabolic syndrome (MS) ${ }^{4}$.

The most widely accepted classifications for defining the MS are as laid down by the World Health Organization (WHO) in 1999 ${ }^{5}$, the European Group for the study of Insulin Resistance (EGIR), also of $1999^{6}$, the Third Report of the National Cholesterol Education Program Expert Panel on Detection, Evaluation and Treatment of High Blood Cholesterol in Adults (ATP III), of 2001 ${ }^{7}$, and the American Association of Clinical Endocrinologists (AACE
IRS $)^{8}$. The ATP III and International Diabetes Federation (IDF) definitions were published more recently, in $2005^{9,10}$.

Estimations of the prevalence of the MS vary considerably, partly because of the different diagnostic

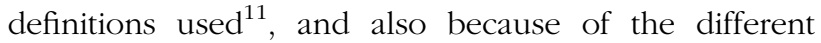
demographic regions studied and the varying study duration $^{12}$. In Spain, only very partial data of the exact prevalence of MS are known because the epidemiological studies available are complex and often only provide estimations of the prevalence in a specific area or population $^{13-16}$.

This study was intended to assess the prevalence of the MS in a sample of patients with overweight and obesity who have attended consecutive consultations for this problem, using the ATP III ${ }^{9}$ and IDF $^{10}$ definitions. 


\section{Patients and methods}

An observational study was undertaken of the prevalence of patients attending the endocrinology and general nutrition outpatient clinics of a hospital in the A Coruña health area and a hospital in the Granada health area over the 1996-2003 period. All adults over 18 years of age with a clinical diagnosis of overweight or obesity who gave their informed consent were consecutively included for evaluation. In addition to patient refusal to take part, exclusion criteria included the presence of neoplastic disease under treatment, pregnancy, heart failure and steroid treatment. Patients with a prior diagnosis of hypertension or dyslipidemia or diabetes under treatment were admitted, but a record was maintained of the medication schedule and dosage administered. Only those patients for whom all the anthropometric and biochemical parameters used to define the MS, both according to the ATP IIII and the IDF were available, were selected. The final study sample consisted of 285 patients, 198 females (69.5\%) and 87 males (30.5\%), diagnosed of overweight or obesity using the criteria defined by the World Health Organization (WHO) in $1998^{17}$.

The anthropometric parameters included weight, height, body mass index (BMI), hip and waist perimeter (wp), waist-to-hip ratio, and sagittal perimeter was measured using standard methods. Weight was measured in kilograms using Seca ${ }^{\circledR}$ scales, and height was measured in centimeters using the Holtain ${ }^{\circledR}$ stadiometer. BMI was calculated by dividing the weight in kilograms by the height in square meters. The waist perimeter in centimetre was measured with a tape measure at a point midway between the last rib and the iliac crest, with the patient standing and on expiration, while hip circumference in centimetre was measured around the buttocks at the level of the greater trochanters with the patient in a standing position. The waist-to-hip ratio was calculated by dividing the value of the waist by the value of the hip. Anthropometric evaluation of regional fat distribution, estimated by waist perimeter and waist-tohip ratio, was carried out based on the same criteria.

Blood samples were taken after a 12-hour overnight fast, and plasma was separated immediately by refrigerated centrifugation at $2500-3000 \mathrm{rpm}$ for a period of $10 \mathrm{~min}$.

The samples were processed immediately or in the first week following preservation at $-20^{\circ} \mathrm{C}$. Total cholesterol (TC), triglycerides (TG) and cholesterol bound to HDL were determined using enzymatic methods ${ }^{18,19}$ in a Technicon ${ }^{\circledR}$ analyzer RA ${ }^{\mathrm{TM}} 1000$. Glucose was measured via an enzymatic method ${ }^{20}$, and insulin was determined using a radioimmunoassay ${ }^{21}$.

Blood pressure was measured with an approved sphygmomanometer after a $10-$ min rest period in a supine position; two separate measurements were performed with a 5-min interval. The criterion for hypertension was current use of antihypertensive treatment in patients diagnosed of hypertension and with a systolic or diastolic blood pressure $\geq 130 \mathrm{mmHg}$ or $\geq 85 \mathrm{mmHg}$ respectively, according to ATP III and IDF criteria. Patients with a prior diagnosis of hypertension and with normal pressure values at the time of evaluation were considered to be hypertensive patients.

To estimate the prevalence of MS, the definitions most widely used in clinical practice, namely those of the ATP III and IDF, were considered. While the criteria used are common to both classifications, each of them has a different diagnostic cutoff point for both central obesity and basal glucose (Table 1).

\section{Statistical analysis}

Descriptive analysis was performed of all the variables collected, and 95\% confidence intervals were calculated. A $\chi^{2}$ test or a Fisher's exact test was used, and the odds ratio (OR) and its 95\% confidence intervals were calculated. A Student's $t$-test or a Mann-Whitney test was used to compare between-group numerical parameters, after checking normality with the Kolmogorov-Smirnov test. Values of $P<0.05$ were considered significant. All the tests were two-sided. The statistical analysis was carried out with SPSS 12.0 for Windows and EpiInfo software.

\section{Results}

A total of 285 patients with a mean age of 40.41 years $(\mathrm{SD}=13.95)$ were studied. Of these, 198 were females

Table 1 Diagnostic criteria for metabolic syndrome using the ATP III and IDF definitions

(A) Third Report of the National Cholesterol Education Program (NCEP) Expert Panel on Detection, Evaluation and Treatment of High Blood Cholesterol in Adults (ATPIII) 2005

Three or more of the following criteria:

1. Central obesity: waist perimeter $>102 \mathrm{~cm}$ in males and $>88 \mathrm{~cm}$ in females.

2. Hypertriglyceridaemia: triglyceride levels $\geq 150 \mathrm{mg} \mathrm{dl}^{-1}$ $\left(\geq 1.7 \mathrm{mmoll}^{-1}\right)$ or specific treatment.

3. $\mathrm{HDL}<40 \mathrm{mg} \mathrm{dl}^{-1}\left(<1.1 \mathrm{mmoll}^{-1}\right)$ in males and $<50 \mathrm{mg} \mathrm{dl}^{-1}$ $\left(<1.3 \mathrm{mmoll}^{-1}\right)$ in females or specific treatment.

4. Hypertension: systolic $\mathrm{BP} \geq 130 \mathrm{mmHg}$ or diastolic $\mathrm{BP} \geq 85$ $\mathrm{mmHg}$ or antihypertensive treatment treatment.

5. Fasting plasma glucose $\geq 100 \mathrm{mg} \mathrm{dl}^{-1}\left(\geq 5.6 \mathrm{mmoll}^{-1}\right)$ or drug treatment for elevated blood glucose.

(B) International Diabetes Federation (IDF) 2005

Central obesity: waist perimeter $\geq 94 \mathrm{~cm}$ in males and $\geq 80 \mathrm{~cm}$ in females plus two of the following criteria:

1. Hypertriglyceridaemia: triglycerides $\geq 150 \mathrm{mg} \mathrm{dl}^{-1}\left(\geq 1.7 \mathrm{mmoll}^{-1}\right)$ or specific treatment.

2. $\mathrm{HDL}<40 \mathrm{mg} \mathrm{dl}^{-1}\left(<1.1 \mathrm{mmoll}^{-1}\right)$ in males and $<50 \mathrm{mg} \mathrm{dl}^{-1}$ $\left(<1.3 \mathrm{mmoll}^{-1}\right)$ in females or specific treatment.

3. Hypertension: systolic $\mathrm{BP} \geq 130 \mathrm{mmHg}$ or diastolic $\mathrm{BP} \geq 85$ $\mathrm{mmHg}$ or specific antihypertensive treatment.

4. Fasting plasma glucose $\geq 100 \mathrm{mg} \mathrm{dl}^{-1}\left(\geq 5.6 \mathrm{mmoll}^{-1}\right)$ or prior diagnosis of type 2 diabetes mellitus.

HDL - high-density lipoprotein cholesterol. 
Table 2 Anthropometric and biochemical characteristics of the study subjects (with overweight and obesity)

\begin{tabular}{|c|c|c|c|}
\hline & $\begin{array}{l}\text { Males }(n=87) \\
\quad \text { Mean }(\mathrm{SD})\end{array}$ & $\begin{array}{l}\text { Females }(n=198) \\
\text { Mean (SD) }\end{array}$ & $P$ \\
\hline Systolic blood pressure $(\mathrm{mmHg})$ & $126.2( \pm 10.8)$ & $125.1( \pm 13.7)$ & 0.074 \\
\hline Diastolic blood pressure (mmHg) & $74.0( \pm 7.0)$ & $73.2( \pm 7.2)$ & 0.491 \\
\hline Waist circumference $(\mathrm{cm})$ & $104.1( \pm 1.6)$ & $91.0( \pm 12.8)$ & $<0.001$ \\
\hline $\mathrm{HDL}\left(\mathrm{mg} \mathrm{dl}^{-1}\right)$ & $47.3( \pm 45.9)$ & $51.5( \pm 16.4)$ & $<0.001$ \\
\hline Triglycerides $\left(\mathrm{mg} \mathrm{dl}^{-1}\right)$ & $158.1( \pm 102.7)$ & $117.2( \pm 58.0)$ & 0.003 \\
\hline Fasting glucose $\left(\mathrm{mg} \mathrm{dl}^{-1}\right)$ & $102.6( \pm 30.3)$ & $101.5( \pm 25.8)$ & 0.837 \\
\hline \multirow[t]{2}{*}{ Body mass index } & $32.8( \pm 4.2)$ & $32.2( \pm 5.4)$ & 0.083 \\
\hline & $\%$ & $\%$ & \\
\hline Waist circumference $\geq 94 \mathrm{~cm}$ ot and $\geq 80 \mathrm{~cm}$ & 77.8 & 79.3 & 0.786 \\
\hline Waist circumference $\geq 102 \mathrm{~cm}$ ot and $\geq 88 \mathrm{~cm} q$ & 61.2 & 54.3 & 0.129 \\
\hline Triglycerides $\geq 150 \mathrm{mg} \mathrm{dl}^{-1}\left(\geq 1.7 \mathrm{mmoll}^{-1}\right)$ or treatment & 36.8 & 19.8 & $<0.001$ \\
\hline $\mathrm{HDL}<40 \mathrm{mg} \mathrm{dl}^{-1}(<1.1 \mathrm{~mm} / \mathrm{dl})$ of and $50 \mathrm{mg} \mathrm{dl}^{-1}\left(1.3 \mathrm{mmoll}^{-1}\right)$ o or treatment & 49.3 & 59.3 & 0.049 \\
\hline $\begin{array}{l}\text { Glucose } \geq 100 \mathrm{mg} \mathrm{dl}^{-1}\left(\geq 5.6 \mathrm{mmol}^{-1}\right) \text { or prior diagnosis of type } 2 \text { diabetes } \\
\text { mellitus or treatment }\end{array}$ & 34.9 & 36.0 & 0.852 \\
\hline Hypertension $\geq 130 / 85 \mathrm{mmHg}$ or treatment & 45.2 & 36 & 0.178 \\
\hline
\end{tabular}

SD - standard deviation; HDL - high-density lipoprotein cholesterol.

Table 3 Prevalence of metabolic syndrome according to ATP III and IDF

\begin{tabular}{lccc}
\hline & \multicolumn{3}{c}{ Total } \\
\cline { 2 - 4 } Definitions & $n$ & $\%$ & $95 \% \mathrm{Cl}$ \\
\hline ATP III & 118 & 41.4 & $35.7-47.4$ \\
IDF & 117 & 41.1 & $35.3-47.0$
\end{tabular}

ATP III - Third Report of the National Cholesterol Education Program Expert Panel on Detection, Evaluation and Treatment of High Blood Cholesterol in Adults; IDF - International Diabetes Federation.

(69.5\%) and 87 males (30.5\%). The proportion of subjects with overweight was $35.4 \%(n=101)$, while patients with obesity represented $64.6 \%(n=184)$. Males were seen to have a worse metabolic pattern, with significantly increased anthropometric parameters and lipid levels (Table 2).

Prevalence of MS was different according to the two definitions used. When the ATP III definition was applied, the total prevalence was $41.4 \%(\mathrm{CI}=35.7-47.4)$, while prevalence according to IDF criteria was $41.1 \%$ (CI = 35.3-47.0). Only one patient diagnosed of MS according to the ATP III criteria did not meet the IDF criteria (Table $3)$. On the other hand, $33(16.5 \%)$ patients who did not meet the ATP III criteria were diagnosed of MS using the IDF criteria. Regardless of the definition used, a higher prevalence of MS was found in men as compared to women, but the difference was not significant. Using the ATP III definition, MS prevalence was $43.7 \%$ in males and $40.4 \%$ in females (OR $=0.87 ; P=0.605)$, while according to the IDF definition, MS was diagnosed in $42.5 \%$ of men as compared to $40.4 \%$ of women $(\mathrm{OR}=0.92 ; P=0.737)$ (Table 4).

According to the ATP III classification, MS prevalence was $18.8 \%$ in overweight patients, and $53.8 \%$ in obese patients $(P<0.001)$. Using the IDF definition, the
Table 4 Prevalence of metabolic syndrome according to ATP III and IDF by sex

\begin{tabular}{|c|c|c|c|c|c|c|}
\hline & \multicolumn{2}{|c|}{ Males } & \multicolumn{2}{|c|}{ Females } & \multirow[b]{2}{*}{$P$} & \multirow[b]{2}{*}{ OR $(95 \% \mathrm{Cl})$} \\
\hline & $n$ & $\%$ & $n$ & $\%$ & & \\
\hline \multirow{4}{*}{$\begin{array}{l}\text { ATP III } \\
\text { IDF }\end{array}$} & 38 & 43.7 & 80 & 40.4 & 0.605 & $0.87(0.52-1.45)$ \\
\hline & 37 & 42.5 & 80 & 40.4 & 0.737 & $0.92(0.55-1.52)$ \\
\hline & \multicolumn{2}{|c|}{ Overweight } & \multicolumn{2}{|c|}{ Obesity } & & \\
\hline & $n$ & $\%$ & $\bar{n}$ & $\%$ & $P$ & OR $(95 \% \mathrm{Cl})$ \\
\hline ATP III & 19 & 18.8 & 99 & 53.8 & $<0.001$ & 5.03 (2.82; 8.95) \\
\hline & 18 & 17.8 & 99 & 53.8 & $<0.001$ & $5.4(3.0-9.6)$ \\
\hline
\end{tabular}

OR - odds ratio; $\mathrm{Cl}$ - confidence interval; ATP III - Third Report of the National Cholesterol Education Program Expert Panel on Detection, Evaluation and Treatment of High Blood Cholesterol in Adults. IDF International Diabetes Federation. Overweight: body mass index $\geq 25$ to $<30 \mathrm{~kg} \mathrm{~m}^{-2}$. Obesity - body mass index $>30 \mathrm{~kg} \mathrm{~m}^{-2} ; \mathrm{SD}-$ standard deviation; HDL - high-density lipoprotein cholesterol.

prevalence of MS was $17.8 \%$ in overweight patients and $53.8 \%$ in obese patients $(P<0.001)$. Establishing the degrees of obesity defined by the SEEDO $2000^{16}$, a steady rise is seen in MS prevalence as the BMI of patients increases, both for the ATP III and the IDF definitions. This is more marked in men, but the difference is not statistically significant (Table 4, Figs. 1 and 2).

No differences were also seen in the number of components of the ATP III or IDF definitions between males and females. Thus, it was shown that $24.2 \%, 33.3 \%, 13.6 \%$ and $28.8 \%$ of females met $0,1,2,3$ or more criteria of the ATP III definition, respectively, while the corresponding proportions in males were $20.7 \%, 27.6 \%, 19.5 \%$ and $32.2 \%$. When the IDF criteria were applied, 29.5\%, 16.8\%, $32.2 \%$ and $21.5 \%$ of females met $0,1,2,3$ or more criteria, respectively, as compared to $23.8 \%, 17.5 \%, 30.2 \%$ and 28.6\% of males, respectively (Figs. 3 and 4 ). 


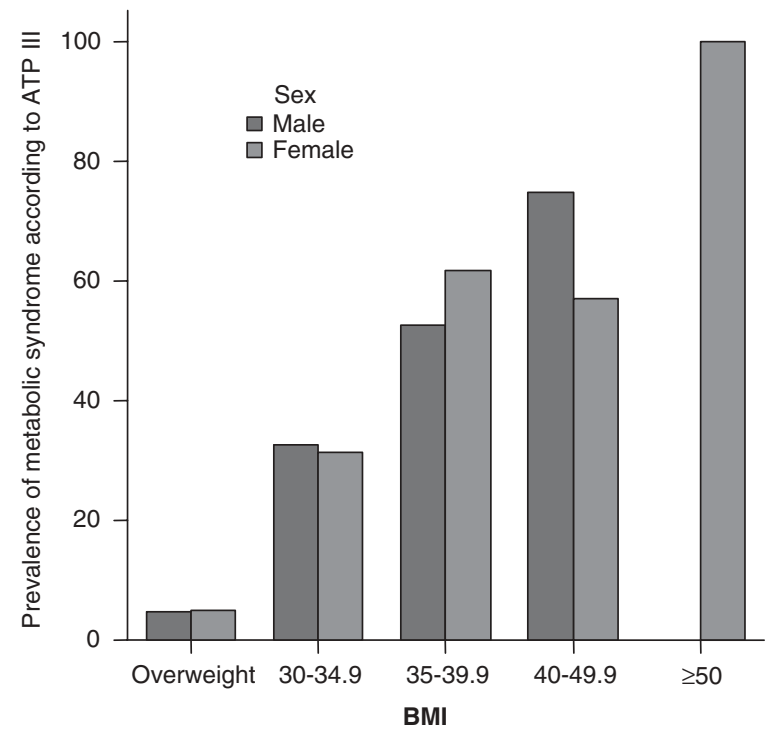

Fig. 1 Prevalence of metabolic syndrome (MS) according to ATP III, by body mass index (BMI) and sex. ATP III: Third Report of the National Cholesterol Education Program (NCEP) Expert Panel on Detection, Evaluation and Treatment of High Blood Cholesterol in Adults

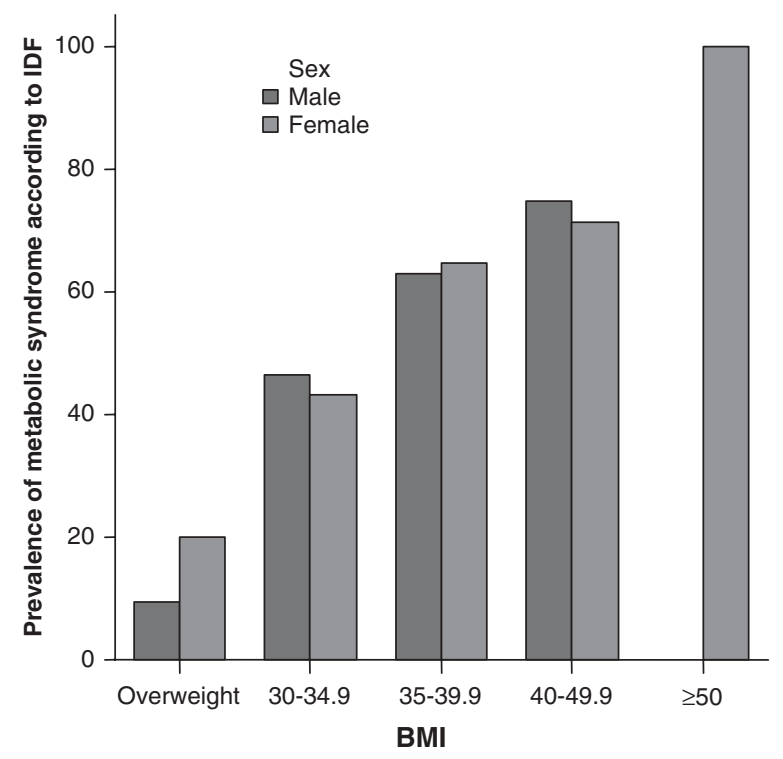

Fig. 2 Prevalence of metabolic syndrome (MS) according to the International Diabetes Federation (IDF), distributed by body mass index (BMI) and sex

Finally, Table 5 shows the prevalence of each of the factors associated with the presence of MS according to the two classifications by sex and body mass index. It is seen that the presence of central obesity was the most prevalent parameter among the MS criteria, according to both the ATP III (53.5\%) and the IDF (78.8\%) definition. The prevalence of all changes is increased among obese patients as compared to overweight patients, with a greater difference being noted among females. This

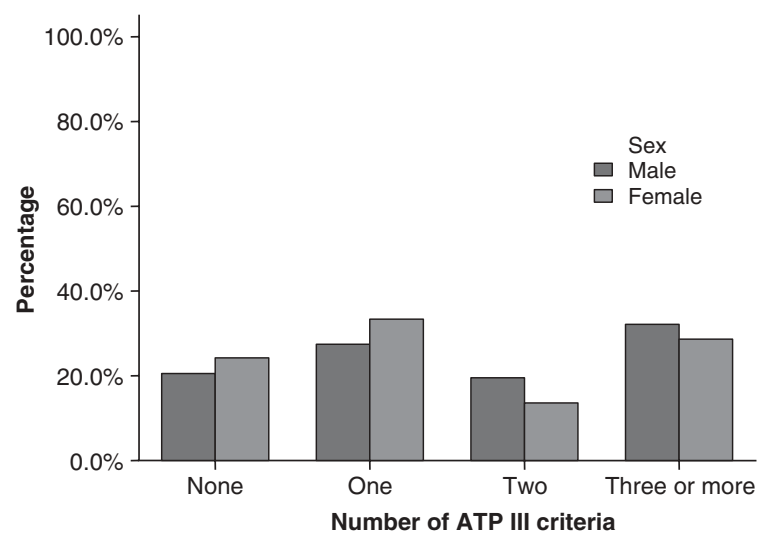

Fig. 3 Sex distribution of the study population according to the number of ATP III criteria used to define the metabolic syndrome they meet. ATP III: Third Report of the National Cholesterol Education Program (NCEP) Expert Panel on Detection, Evaluation and Treatment of High Blood Cholesterol in Adult

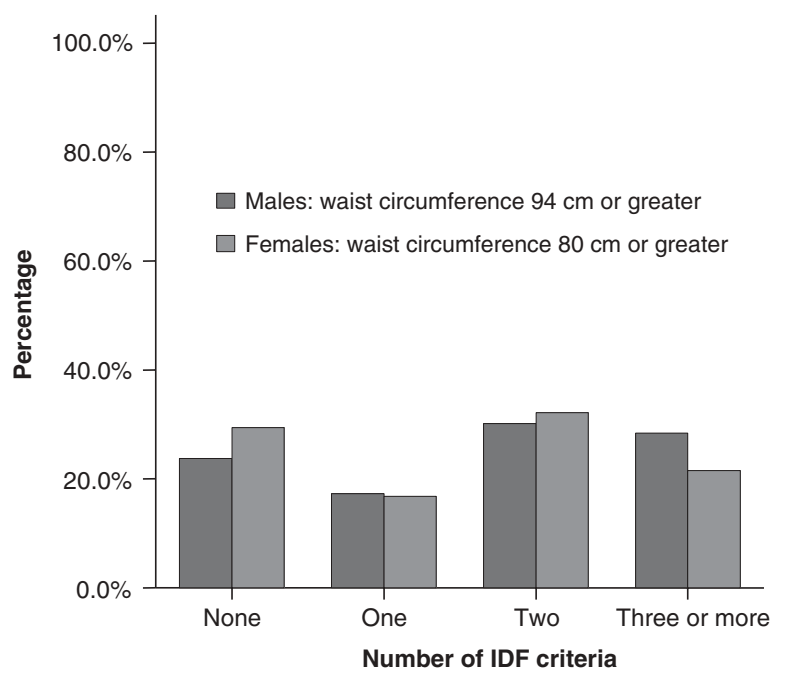

Fig. 4 Sex distribution of the study population according to the number of International Diabetes Federation (IDF) criteria used to define the metabolic syndrome they meet

increase is more marked in the following risk factors: hyperglycaemia (28.6\% vs. $36.9 \%$ in males; $18.8 \%$ vs. $47.9 \%$ in females); hypertension (22.2\% vs. $46.7 \%$ in males; $14.6 \%$ vs. $37.9 \%$ in females); waist perimeter, as defined both by the ATP III (0\% vs. $74.2 \%$ in males; $14.5 \%$ vs. $77.7 \%$ in females) and by the IDF ( $42.1 \%$ vs. $88.7 \%$ in males; $55.3 \%$ vs. $95.5 \%$ in females); and triglyceride levels (23.8\% vs. $46.9 \%$ in males; $10.1 \%$ vs. $31.4 \%$ in females).

\section{Discussion}

The existence of multiple definitions of the MS has caused confusion, despite the fact that different expert groups have attempted to establish a more precise definition of 
the syndrome ${ }^{5-7}$. Accurate estimations of MS prevalence are therefore difficult. The prevalence of MS has been estimated to be approximately $20-25 \%$ of the population at large ${ }^{22}$. People with MS have a two-fold higher risk of mortality and a three-fold higher risk of experiencing a cardiovascular event as compared to people without MS $^{2}$. While the definitions most widely used are those of ATP III, WHO and EGIR, the IDF reached in May 2005 a consensus for defining the MS, taking into account the opinion of experts from all over the world, including diabetologists, cardiologists, lipidologists, epidemiologists, geneticists and experts on metabolism and nutrition. All above definitions include among their criteria estimations of abdominal obesity, high blood pressure, dyslipidemia and hyperglycaemia. However, is should be noted that some of these criteria used to define MS are ambiguous or incomplete ${ }^{5,7,23}$. For instance, it is not clear whether the definition of blood pressure is $\geq 130$ and $85 \mathrm{mmHg}$, or if it is systolic blood pressure $\geq 130 \mathrm{mmHg}$ or diastolic blood pressure $>85 \mathrm{mmHg}$. Similarly, it has not been defined whether blood pressure should be measured with the patient sitting or in a supine position, or whether one or two serial measurements with a 5-min interval should be made. This ambiguity will affect the sensitivity and specificity of MS diagnosis. Similarly, the impact of false positive or false negative results has not been calculated either. The ATP III and IDF definitions are possibly the ones proving to be most straightforward in daily clinical practice, because they are based on easily obtained anthropometric and laboratory measurements ${ }^{24}$. The WHO definition is more difficult to apply for a number of reasons ${ }^{25}$. The first of these is the need to perform an oral glucose tolerance test in some patients, when the current trend set by the American Diabetes Association (ADA) is not to perform this test for diagnosis in risk patients, but to establish instead increasingly lower cutoff points in fasting blood glucose values. The second reason is that microalbuminuria is infrequently measured in standard clinical practice in non-diabetic patients, and the final reason is that basal blood insulin is not routinely measured, and its concentrations are not properly standardised $^{26}$. Moreover, a specific cutoff point has not been established in basal insulin values for the calculation of insulin resistance.

The main differences between the ATP III and IDF classifications used in this study lie in the central obesity criterion, as each definition uses different cutoff points. The IDF emphasises ethnic differences in the correlation between abdominal obesity and MS risk factors. The IDF also believes it essential for MS diagnosis that the waist perimeter criterion should be met, but it should be considered in a closer correlation with insulin resistance than other risk factors, unlike the ATP III definition, for which it would not be required for diagnosing MS if other three criteria are present. 
Both definitions used in this study consider fasting glucose values $\geq 100 \mathrm{mg} \mathrm{dl}^{-1}$, by applying the ADA criterion for altered basal blood glucose of glycaemia ${ }^{27}$, unlike previous classifications of MS.

Will this difference in cutoff points improve the value of MS for predicting cardiovascular risk? In a study conducted in males with MS, Lakka et $a l^{28}$ found that CVD and mortality were more prevalent when a waist circumference of $102 \mathrm{~cm}$ was used as compared to a waist circumference of $94 \mathrm{~cm}$. Other investigators ${ }^{29}$ showed that lowering the diagnostic cutoff point of altered basal glycaemia from 110 to $100 \mathrm{mg} \mathrm{dl}^{-1}$ did not result in any change in the calculation of the odds ratio for estimating the risk of CVD, although the number of individuals identified increased. Similarly, there is no evidence to warrant the use of different cutoff points by sex, race or ethnic group in order to define the MS criteria as cardiovascular risk predictors, although the American Heart Association (AHA) and the National Heart, Lung and Blood Institute (NHLBI) ${ }^{30}$ think that the waist circumference cutoff point should be different depending on the ethnic group, because they believe that some ethnic groups (e.g. Asian Americans) are particularly prone to insulin resistance and MS with only moderate waist circumference increases (e.g. $\geq 90 \mathrm{~cm}$ in males and $\geq 80 \mathrm{~cm}$ in females).

Of the five classifications, only the EGIR and AACE exclude diabetes as a diagnostic criterion for the MS, in contrast to the ATP III, WHO and IDF definitions; this is a controversial point ${ }^{31}$. Apart from the IDF and ATP III 2005, no definition explicitly includes the use of medications for high blood pressure or dyslipidaemia as part of the definition.

It should be borne in mind that estimation of the prevalence of MS in this study was carried out in a white European population. This fact is important for data interpretation, because the prevalence of the MS varies according to the different population studies. An interesting demonstration of the effect of race on the MS is the comparison of its prevalence, defined according to the ATP III criteria, in studies conducted in Finnish males ${ }^{32}$ and American Indians ${ }^{33}$. These studies included agematched subjects and reported MS prevalences of 14\% in Finnish subjects and $43.6 \%$ in American Indians. This difference may be due to a lower prevalence of atherogenic dyslipidaemia in the white population ${ }^{22}$. MS prevalence appears to be higher when the WHO definition is used as compared to the ATP III criteria, and even more so when compared to the prevalence using the EGIR definition. Such difference is more marked among men, particularly between the EGIR and the WHO definitions. No data are yet available from epidemiological studies using the IDF definition. The prevalence of MS using the ATP III, EGIR and WHO definitions was analyzed in two studies, one by an Australian group ${ }^{34}$ and the other, the Mauritius study ${ }^{35}$. In these studies, MS prevalence using the WHO definition was higher than when the EGIR or ATP III definitions were used. In the Mauritius study, MS prevalence in men using the ATP III, EGIR and WHO definitions was $10.6 \%$, $9 \%$ and $20.9 \%$, respectively. The corresponding values for women were $14.7 \%, 10.2 \%$ and 17.6\%. In the Australian study (AusDiab study), the prevalence of MS among males was 19.5\%, 18.6\% and 25.2\% using the ATP III, EGIR and WHO definitions, respectively, and prevalence in females was $17.2 \%, 13.3 \%$ and $16.7 \%$, respectively. This difference between the three classifications is seen in this study, which found prevalence values of the MS in males of $32.7 \%, 20.5 \%$ and $44 \%$ with the ATP III, EGIR and WHO definitions, respectively. A similar difference was also found in women, in whom the prevalence of MS was 25.5\%, 13.6\% and $32.2 \%$, respectively. A possible explanation as to why MS prevalence cannot exceed 25\% when the EGIR definition is used is that the first criterion of such definition involves having basal insulin levels above the 75th percentile for a non-diabetic population. It should be noted that the variation in MS prevalence among men and women in the different populations using the ATP III and WHO criteria is not so marked as when the EGIR definition is applied.

When it comes to interpreting the higher prevalence of MS apparent in this study as compared to other previously reported studies, it should be taken into account that subjects included in this study had overweight or obesity, unlike in an epidemiological study of the population at large. The association between the prevalence of the MS and BMI was also evaluated in a recent study of the Third National Health and Nutrition Examination Survey, which shows an increment of the prevalence of MS in patients with overweight and obesity. They find that 4,6\%, 22.4\% and $59.6 \%$ of normal-weight, overweight and obese men met the MS diagnostic criteria, with similar results in women ${ }^{36}$.

In the present study, the prevalence of all changes is substantially increased among obese patients as compared to overweight patients, but we are unable to establish whether this difference is significant or not, probably because of the limited number of patients in each comparison group. In both the ATP III and IDF classifications, the presence of central obesity is the most prevalent parameter among the MS criteria. This fact was also observed in other studies, such as the Insulin Resistance in Atherosclerosis Study (IRAS) ${ }^{37}$. In both definitions, waist perimeter was used to evaluate central obesity, but with a different cutoff point. Based on the results of the participants in the Han et $a l^{38}$ and Lean et $a l^{39}$ studies, three levels of cardiovascular risk were established according to the waist perimeter cutoff point. They proposed that a waist circumference value less than $94 \mathrm{~cm}$ in men and $80 \mathrm{~cm}$ in women would be low risk; the $94-102 \mathrm{~cm}$ range in men and $80-88 \mathrm{~cm}$ in women would be an intermediate risk; and a value above $102 \mathrm{~cm}$ in men 
and $88 \mathrm{~cm}$ in women would be high risk, in which case medical attention and a weight loss program would be indicated. The ATP III adopted this last level as the criterion for MS. The IDF, however, uses the intermediate risk range as the criterion for MS diagnosis.

\section{Conclusions}

The results of this study show a higher prevalence of the MS in the population of patients with overweight or obesity as compared to a general population, as was to be expected. Few prevalence studies have been performed, but they all report the difference between the various classifications, showing that they are probably not measuring the same thing. Although the ATP III and IDF definitions are easier to apply in daily clinical practice, we think that further studies are required to ascertain their correlation with insulin resistance, so that criteria may be unified when it comes to defining MS, and a more valid comparison may be made of the worldwide extent of this epidemic.

\section{Acknowledgements}

A.S. had the original idea, analysed the data, wrote the first draft, and edited subsequent versions. D.B. and M.B. analysed the data, and edited the manuscript, S.P. carried out the statistical analysis, D. de Luis supervised the field data collection, and M. Lopez de la Torre supervised the study and edited the manuscript.

\section{References}

1 Haffner SM, Valdez RA, Hazuda HP, Mitchell BD, Morales PA, Stern MP. Prospective analysis of the insulin-resistance syndrome (syndrome X). Diabetes 1992; 41(6): 715-22.

2 Isomaa B, Almgren P, Tuomi T, Forse'n B, Lahti K, Nisse'n $\mathrm{M}$, et al. Cardiovascular morbidity and mortality associated with the metabolic syndrome. Diabetes Care 2001; 24(5): 683-9.

3 Reaven GM. Banting lecture 1988: role of insulin resitance in human disease. Diabetes 1988; 37(12): 1595-607.

4 Grundy SM. Hypertriglyceridemia, insulin resistance, and the metabolic syndrome. American Journal of Cardiology 1999; 83(9B): 25F-9F.

5 World Health Organization. Definition, diagnosis and classification of diabetes mellitus and its complications. Report of a WHO Consultation. Geneva: Department of Non-communicable Disease Surveillance, World Health Organization, 1999.

6 Balkau B, Charles MA, Comment on the provisional report from the WHO consultation. European Group for Study of Insulin Resistance (EGIR). Diabetic Medicine 1999; 16(5): 442-3.

7 Expert Panel on Detection. Evaluation and treatment of high blood cholesterol in adults: executive summary of the third report of the National Cholesterol Education Program (NCEP) expert panel on detection, evaluation, and treatment of high blood cholesterol in adults (Adult Treatment
Panel III). Journal of the American Medical Association 2001; 285(19): 2486-97.

8 American College of Endocrinology Task Force on the Insulin Resistance Síndrome. American College of Endocrinology Position Statement on the insulin resistance syndrome. Endocrine Practice 2002; 9(1): 236-52.

9 Kahn R, Buse J, Ferrannini E, Stern M. The metabolic syndrome: time for a critical appraisal. Diabetes Care 2005; 28(5): 2289-304.

10 International Diabetes Federation. Worldwide definition of the metabolic syndrome. Available at: http://www.idf.org/ webdata/docs/IDF_Metasyndrome definition.pdf. Accessed August 24, 2005.

11 Schmidt MI, Duncan BB, Watson RL, Sharrett AR, Brancati FL, Heiss G. A metabolic syndrome in whites and AfricanAmericans: the Atherosclerosis Risk in Communities Baseline Study. Diabetes care 1996; 19(5): 414-18.

12 Liese AD, Mayer-Davis EJ, Trroler HA, Davis CE, Keil U, Scmidt MI, et al. Familial components of the multiple metabolic síndrome: the ARIC study. Diabetología 1997; 40(8): 963-70.

13 Álvarez León EE, Ribas Barba L, Serra Majem L. Prevalencia del síndrome metabólico en la población de las Islas Canarias. Medicina Clinica (Barcelona) 2003; 120(5): $172-4$.

14 Hernández A, Riera C, Solá E, Oliver MJ, Martínez ML, Morillas C, et al. Prevalencia del síndrome metabólico entre pacientes con cardiopatía isquémica. Medicina Clinica (Barcelona) 2003; 121(6): 204-8.

15 Ascaso JF, Romero P, Real JT, Lorente RI, Martínez-Valls J, Carmena R. Abdominal obesity, insulin resistance, and metabolic syndrome in a Southern European population. European Journal of Internal Medicine 2003; 14(2): 101-6.

16 Alvarez Cosmea A, López Fernández V, Suárez García S, Arias García T, Prieto Díaz MA, Díaz González L. Diferencias en la prevalencia del síndrome metabólico según las definiciones del ATP III y la OMS. Medicina Clinica (Barcelona) 2005; 124(10): 368-70.

17 WHO Consultation on obesity. Preventing and managing the global epidemic. Geneva: WHO, 1998.

18 Allain CC, Poon LS, Chan CSG, Richmod WPC. Enzymatic determination of total serum cholesterol. Clinical Chemistry 1979; 20(4): 470-5.

19 Ter HF, Baarscheer T, Fiolet JWT. Influence of free glycerol on enzymatic of triglycerides. Clinical Chemistry 1984; 30(6): 1102-3.

20 Trinder P. Enzymatic colorimetric method for glucose determination. Annals of Clinical Biochemistry 1969; 6(4): 24-7.

21 Berson S, Yellow RS. Quantitative aspects of the reaction between insulin and insulin-binding antibody. Journal of Clinical Investigation 1959; 38: 1996-2016.

22 Dunstan DW, Zimmet PZ, Welborn TA, De Courten MP, Cameron AJ, Sicree RA, et al. The rising prevalence of diabetes and impaired glucose tolerance. The Australian Diabetes, Obesity and Lifestyle Study. Diabetes Care 2002; 25(5): 829-34.

23 Grundy SM, Brewer Jr HB, Cleeman JI, Smith Jr SC, Lenfant C. American Heart Association; National Heart, Lung, and Blood Institute. Definition of metabolic syndrome: Report of the National Heart, Lung, and Blood Institute/American Heart Association conference on scientific issues related to definition. Circulation 2004; 109(3): 433-8.

24 Ford ES, Giles WH, Mokdad AH. Increasing prevalence of the metabolic syndrome among U.S. Adults. Diabetes Care 2004; 27(10): 2444-9.

25 Hu G, Qiao Q, Tuomilehto J, Balkau B, Borch-Johnsen K, Pyorala K, DECODE Study Group. Prevalence of the metabolic syndrome and its relation to all-cause and cardiovascular mortality in nondiabetic European men 
and women. Archives of Internal Medicine 2004; 164(10): 1066-76

26 Robbins DC, Andersen L, Bowsher R, Chance R, Dinesen B, Frank B, et al. Report of the American Diabetes Association's task force on standardization of the insulin assay. Diabetes 1996; 45(2): 242-56.

27 American Diabetes Association. Diagnosis and Classification of Diabetes Mellitus. Diabetes Care 2005; 28(Suppl. 1): S37-42.

28 Lakka HM, Laaksonen DE, Lakka TA, Niskanen LK, Kumpusalo E, Tuomilehto J, et al. The metabolic syndrome and total and cardiovascular disease mortality in middle-aged men. Journal of the American Medical Association 2002; 288(21): 2709-16.

29 McNeill AM, Rosamond WD, Girman CJ, Golden SH, Schmidt MI, East HE, et al. The metabolic syndrome and 11-year risk of incident cardiovascular disease in the Atherosclerosis Risk in Communities Study. Diabetes Care 2005; 28(2): 385-90.

30 Grundy SM, Cleeman JI, Daniel SR, Donato KA, Eckel RH, Franklin BA, et al. American Heart Association. National Heart, Lung, and Blood Institute. Diagnosis and management of the metabolic syndrome. Circulation 2005; 112(17): 2735-52.

31 Kahn R, Buse J, Ferrannini E, Stern M. The metabolic syndrome: time for a critical appraisal. Diabetes Care 2005; 28(9): 2289-304.

32 Laaksonen DE, Lakka HM, Niskanen LK, Kaplan GA, Salonen JT, Lakka TA. Metabolic syndrome and development of diabetes mellitus: application and validation of recently suggested definitions of the metabolic syndrome in a prospective cohort study. American Journal of Epidemiology 2002; 156(11): 1070-7.

33 Resnick HE. Metabolic syndrome in American Indians. Diabetes Care 2002; 25(7): 1246-7.

34 Adrian J Cameron, Timothy A Welborn, Paul Z Zimmet, David W Dunstan, Neville Owen, Jo Salmon, et al. Overweight and obesity in Australia: the 1999-2000 Australian Diabetes, Obesity and Lifestyle Study (AusDiab). The Medical Journal of Australia 2003; 178(9): 427-32.

35 Cameron AJ, Shaw JE, Zimmet PZ, Chitson P, Alberti KGGM, Toumiletho J. Comparison of WHO and NCEP metabolic syndrome definitions over 5 years in Mauritius. Diabetología 2003; 46(2): A3068.

36 Park YW, Zhu S, Palaniappan L, Heshka S, Carnethon MR, Heymsfield SB. The Metabolic Syndrome: prevalence and associated risk factor findings in the US population from the Third National Health and Nutrition Examination Survey, 1988-1994. Archives of Internal Medicine 2003; 163(1): 427-36.

37 Palaniappan L, Carnethon MR, Wang Y, Hanley AJ, Fortmann SP, Haffner SM, et al. Insulin Resistance Atherosclerosis Study. Predictors of the incident metabolic syndrome in adults: the Insulin Resistance Atherosclerosis Study. Diabetes Care 2004; 27(3): 788-93.

38 Han TS, van Leer EM, Seidell JC, Lean ME. Waist circumference action levels in the identification of cardiovascular risk factors: prevalence study in a random sample. British Medical Journal 1995; 311(7017): 1401-5.

39 Lean ME, Han TS, Morrison CE. Waist circumference as a measure for indicating need for weight management. British Medical Journal 1995; 311(6998): 158-61. 